\title{
Formalism In Commercial Papers
}

\author{
Ahmed Fahd Al-Batoosh \\ Assistant Professor, Email: btoosh127@gmail.com \\ Ajloun National University
}

\begin{abstract}
This study aimed to clarify the legal implications of the check when it is empty of all or some of the mandatory formal conditions, and to indicate the optional conditions that may be included in the check. The optional conditions that may not be included in the check because they are inconsistent with its nature. The researcher concluded that the Jordanian legislator and the Iraqi legislator referred to the mandatory data in the check as an exclusive and not an example, by stipulating it in Article (137) of the Iraqi Trade Law and Article (228) of the Jordanian Trade Law. In particular, where the legislator arranged the invalidity of the check that is empty from the date of its creation. However, the check may include optional data that does not contradict with its nature and does not violate any of the peremptory rules or public order and public morals, and finally the researcher recommends the necessity to organize the optional data and indicate its importance, which does not conflict with the nature and essence of the check as is the case with the mandatory data, and not only referring to other articles provisions.
\end{abstract}

Keywords:

check, legislator, formalism , trade papers

Article Received: 18 August 2020, Revised: 3 November 2020, Accepted: 24 November 2020

\section{Introduction:}

Commercial papers arose, in the forefront of which is the bond of withdrawal, under the customary rules as an expression of the commercial activity's need for them as legal means that traders resort to settle debts arising from their transactions, but it is not known precisely the date of their appearance despite the efforts made by researchers in the history of the law. That is because what each of them has reached still needs to be supported and proven due to the scarcity of historical documents that can be relied upon in this regard ${ }^{(1)}$.

In Jordan, commercial papers were subject to the provisions of the Ottoman Trade Law issued on June 18, 1850 CE, which was transferred from the French Law, in addition to the Palestinian policies and checks Law that was applied in Palestine during the British Mandate era that was transferred from the Saxon laws. However, since these laws were transmitted from contradictory legal systems, it was necessary to reconsider the commercial laws applied in Jordan, after the economic progress that the Kingdom had made in order to develop the rules that govern commercial activity in line with what this activity has reached (2).

The Jordanian legislator issued Trade Law No. 12 of $1966 \mathrm{AD}$, quoting its provisions from the Syrian Law taken from the Lebanese and French Laws to be the applicable law that governs all aspects of commercial dealings in Jordan.

In this research, we will focus on the issue of formalism in commercial papers, which is one of the most important systems of commercial law.

Commercial transactions are based on credit, and commercial papers are the instrument of this credit, as the creditor gives credit to the debtor by accepting payment through a withdrawal or bond for an order and waiting until the due date. Article (123) of the Jordanian Trade Law enumerates the types of commercial papers and defines each type of them as : "Commercial papers are negotiable bonds according to the provisions of this law and include the following ... the bond of withdrawal ..... and the

order bond, also called the promissory note, which is known under the name of the bill of exchange ... the check ... and the bearer bond. " 
In this paper, the researcher has discussed a partial issue of commercial papers with regard to formalism in commercial papers (check as a model).

\section{The Problem of the Study:}

The check is considered as a commercial paper that is subject to a certain form that is designed and defined by the law that should be adhered to, and accordingly the problem lies purely through answering a number of questions, including:

1- What are the mandatory formal requirements that the check must be legally fulfilled?

2- What are the optional formal requirements that are consistent with the nature of the check?

3- What are the legal implications of a check if it is free from all or some of the optional or mandatory formal conditions?

\section{The Objectives Of The Study}

The research aims to achieve the following objectives:

1- A statement of the mandatory formal conditions for establishing the check.

2- Clarification of the legal implications of the check when it is empty of all or some of the mandatory formal requirements.

3- An indication of the optional conditions that may be included in the check data and the optional conditions that may not be included in the check because they are inconsistent with its nature .

\section{The Significance Of The Study}

The importance of this research lies in recognizing the importance of the check and the formal conditions of it , and the activation it achieves in the economic life in any country, as it is considered an effective means in facilitating the conclusion of commercial deals, and the importance also appears in explaining the legal implications of not adhering to the formality in the check as a paper Commercial.

\section{Methodology}

The nature of the topic covered by the research requires the researcher to take a specific approach, where the researcher will adopt an integrated and combined methodology to create a comprehensive framework for the analysis, among the most prominent of these approaches are :

1- Descriptive approach: Through this approach, the formal conditions of the check will be described in order to know the importance of these conditions and their legal implications and draw conclusions for their generalization.

2- Analytical approach: This approach is concerned with defining and evaluating the parts that make up the whole for any issue, and it is a means to obtain rich and new knowledge. It is also known that the analytical approach takes different forms and levels according to the nature of the subject of research, and the multiplicity of analysis processes is a condition for providing a more general and comprehensive understanding for the issue under study, as it works to analyze the subject into simple elements or divide the thing into its components and units.

\section{The First Section}

\section{The Nature of Commercial Papers}

Through this study, the concept of the commercial paper and its characteristics will be addressed, according to the following divisions:

The first requirement: the concept of commercial papers

The second requirement: characteristics of commercial papers.

\section{The First Requirement The Concept Of Commercial Papers}

Many countries around the world have included the provisions related to commercial papers in their laws, without seeking to find a specific definition thereof, and the legislator aims to leave the field of jurisprudence wide, in front of jurisprudence and the judiciary, to choose the most appropriate definition, with the possibility of improving it according to the developments of the commercial usages and norms ${ }^{(3)}$.

The Jordanian legislator followed the approach that most commercial legal legislations followed. $\mathrm{He}$ did not set a definition for the commercial paper that includes the elements that distinguish it. Rather, the Jordanian legislator referred in Article (123) of the Jordanian Trade Law, which 
enumerated the types of commercial papers, to the manner in which the fixed rights are traded: "Commercial papers are negotiable bills in accordance with the provisions of this law."

While the Iraqi legislator had been different from the Jordanian legislator and most of the legislations when he included a specific definition of commercial papers in the Iraqi Trade Law, where he defined these papers through Article (39) of it as: "A formal document in a specific form in which a person undertakes or orders another person to pay a specified amount of money at a specific time and place, and it is negotiable by endorsement or handling. "

In any case, commercial papers can be defined, in terms of their function, as : written bonds, fulfilling certain data, according to conditions determined by the law of each country , and including a commercial obligation to pay a single cash amount payable on a specific date, with the possibility of transferring the right, if necessary from one person to another, through endorsement or handling ${ }^{(4)}$.

The legal systems in various countries have endeavored to support, strengthen and protect dealing with these securities, so that they are acceptable among market dealers, and replace money in meeting debts. These laws also aim to economize the use of money and achieve speed in concluding deals and settling obligations ${ }^{(5)}$.

There was a trend that the legislator had set substantive and formal conditions detailed to consider it a paper subject to the provisions of commercial papers, so it is difficult to envision another paper that does not take a form organized by the legislator, and yet it is subject to its provisions, in addition to the fact that the provisions of commercial papers are exceptional provisions that are not subject to expansion in applying them in cases other than those stipulated. He adds this to another opinion that supports the importance of this theoretical dispute because the work has not yet created another commercial paper, and that the disagreement between the two previous opinions has no practical significance after it has been proven that the commercial papers mentioned in the law are sufficient to meet the requirements of commercial life ${ }^{(6)}$.

However, this opinion cannot be accepted as the economic and commercial life is in continuous and rapid development, and modern technological means are capable of creating papers that may resemble commercial papers, and the practical reality is never exhausted from this. Indeed, negotiable certificates of deposit have appeared and are considered as commercial papers because they carry their characteristics and need just to establish the custom for them, as well as the dividends and bond interest coupons, they are also considered as commercial papers that need to be approved by the custom in this capacity ${ }^{(7)}$.

In light of the foregoing, commercial papers can be defined as written instruments according to specific data stipulated by the law whose subject matter is the obligation to pay an amount of money payable upon sight or after a certain time and are negotiable by commercial means.

\section{The Second Requirement}

\section{Characteristics of Commercial Papers}

We mentioned in the first requirement the definition of commercial papers, in terms of their function, as written instruments that fulfill certain data, according to conditions determined by the law of each country. They include a commercial obligation to pay a single monetary sum, due to be paid on a specific date, with the possibility of transferring the right as required, from one person to another, through endorsement or handling ${ }^{(8)}$.

Therefore, many characteristics that distinguish commercial papers can be deduced from the previous definition in form, subject, entitlement, tradability, and protection for the creditor, and these characteristics will be explained successively as follows:

First: In terms of form, the laws of countries required writing, to represent the form that a commercial paper should be like, meaning that the paper should be a permanent written instrument and determine the data, which represent the minimum, that must be included in every commercial paper. That is, the legislator, by drawing specific templates, required that 
commercial papers be drawn up according to them (9).

The formality of the commercial paper varies according to its type (bill of exchange, bond or check), and the formalism aims to facilitate and encourage the circulation of commercial papers. This is because it saves those who will receive the paper the hardship of research and investigation, to verify the solidity of the right affirmed in it, and its freedom from defects that waste that right.

The formality of commercial papers makes him content with just taking a quick look at the paper, to make sure that it includes all the necessary data for its value. It thus fulfilled the required form.

Second: In terms of the subject matter, the right, which is fixed in the commercial paper, must be representative of a certain amount of money. Therefore, the instruments whose subject matter is a commodity, such as bills of lading, are not considered commercial papers. As the bearer of these bonds is not assured of obtaining a certain amount of money, on a specific date, because he may not find a buyer for the goods. If the buyer exists, he may not pay the price the seller expected when purchasing the goods. This is because they are subject to price fluctuations, in the period of its trading ${ }^{(10)}$.

In addition, the fixed amount in the commercial paper must be specified (defined) or assignable. As for the due date of the paper, it may be upon sight or added to a term.

Third: In terms of trading and creditor protection. They are as follows:

1- In terms of circulation, commercial paper takes the place of money in transactions. In doing so, it performs the same function as money in terms of its use as a means of meeting debts and obligations. Therefore, it must be facilitated for circulation among individuals, and be surrounded by guarantees that make individuals reassure that they will be accepted in their dealings as a means of fulfillment. If the commercial paper is its bearer, then the right fixed on it is transferred to the new creditor as soon as it is traded or delivered. If the paper is a order paper, or for a specific person's command, then the right fixed on it is transferred to the endorser, by simply writing a brief on the back of the paper, stating that this right is transferred to another person, and fulfills the signature of the endorser ${ }^{(11)}$.

2- In terms of protecting the creditor, the commercial paper is used, as a means of credit, by liquidating it, i.e. obtaining its value in cash, before its due date, in return for the banks obtaining a small percentage of its value. This procedure is known as discounting commercial paper, which represents a major function of banks. In order to achieve the function of commercial papers as a means of credit, laws have been legislated in various countries to provide the creditor with special protection. So the legislator resorted to severity and cruelty in dealing with those who are committed to the commercial paper, intending to protect the rights of the bona fide bearer $^{(12)}$.

Fourth: In terms of entitlement to due time, which is fixed to the creditor in the commercial paper, it is imperative that the commercial paper be in the hand of this creditor, who is claiming fulfillment. The commercial paper is payable upon view, or added to a term, that is, after a specified period from the date of its issuance. It appears that it is difficult to set this term by a specific period as the matter is due to what is being recognized in commercial circles. However, some commentators believe that the short term ranges between three and six months ${ }^{(13)}$.

\section{The Second Topic \\ The Importance of Formal Requirements in Commercial Papers \\ (a check as a model)}

The check arose, from the beginning, connected to the bank's operations and an outlet for them, as it originated as an easy way to recover the money deposited in the banks, whether this recovery was for the account of the depositor himself, and this is the basis of his origin, or this recovery was for the account of others. It developed and became like a bill and the depositor is authorized to order the bank to pay an amount of money from the 
deposited balance for the order of another person or its bearer called the beneficiary. The check had surpassed the bill that it became more widespread in transactions. It has replaced the bill of exchange and became a tool for executing the exchange contract on the drawee, as well as using it instead of cash ${ }^{(14) .}$.

But what we are interested in studying the check as a commercial paper is the formalism and its importance in it, as the formalism in commercial papers, including the check, is considered one of the foundations on which the exchange law is based, that is, the exchange law makes the commercial paper a legal act formality so that the disposition is not subject to its provisions, unless it is written in a document that includes specific data. Accordingly, the formal conditions necessary for writing the check are that it is written in a document, as writing is necessary for the validity of the commitment that the check contains, in addition to proving it . This document includes mandatory data and optional data, and this is what will be explained successively as follows:

The first requirement: the formal conditions for the issuance of a check

The second requirement: the penalty for breaching the formal requirements

\section{The First Requirement}

\section{Formal Conditions For Issuing A Check}

First, the check must be defined. Article 123 of the Jordanian Trade Law defines the check as: "a document written according to formal conditions stipulated by the law that includes an order from the drawer to the drawee, and it must be a bank in Jordan that pays a third person who is the beneficiary or an order to this person or its bearer an amount of cash as soon as it is seen and writes the check in the form ....."

It is clear from the definition and form of the check and the provisions of the Trade Law that it is similar to a promissory: each of them includes three parties, namely the drawer, the drawee and the beneficiary. The check also assumes, like a promissory, that there are two previous relationships: the first is a relationship between the drawer and the beneficiary which is the basis for issuing the check, and the second is a relationship between the drawer and the bank drawn on and its basis in exchange for fulfillment or balance ${ }^{(15)}$.

As for the Iraqi legislator, he did not define the check directly. Rather, he mentioned a definition of the commercial paper. And since the check is considered a commercial paper, it falls within this definition that was mentioned previously. Also , since the check is a formal document organized according to certain conditions stipulated by the law, it cannot be created without writing it down even if the law did not explicitly stipulate that. The writing requirement can be deduced from the provisions of the law related to this paper, and it is not required to write the check from the drawer himself, since it may be drawn up by another person or through a typewriter, and after that the drawer puts his signature on it . It is customary for banks to distribute checks printed to their customers containing serial numbers that fulfill the legal requirements ${ }^{(16)}$.

The Jordanian legislator has regulated the provisions of the check in Articles (228-281) of the Trade Law. The legislator has derived the rules for the check from the Geneva Conventions concerning the check signed by the Jordanian legislator in $1931^{(17) \text {. }}$

The formal requirements of the check mean those mandatory and necessary data that give the check criminal protection and make it a means of fulfillment, such as cash in financial transactions. These conditions are due to the standard international agreements for the provisions of the check (Geneva 1931) in the first article thereof, and accordingly, almost all the legal texts regulating the conditions are uniform in all countries of the world ${ }^{(18)}$.

With reference to the Jordanian Trade Law, Article (228) stipulates the mandatory data that the check must include, and Article (138) of the Iraqi Trade Law, we find that the legislators stipulated that the check should include the following data: 


\section{First: the word of the "check"}

The legislator requires that the word "check" be mentioned in the body of the voucher and in the language in which it was written . work has been made to mention the word "check" in the body of the bond as follows: "Pay according to this check .......". By this, the legislator wanted to determine the nature and type of the paper to distinguish it from other commercial papers, especially the withdrawal document, and to alert the signatory to the nature of the obligation that results from his signature ${ }^{(19)}$.

\section{Second: The date when and the place where} the check was issued,

- The date when the check was issued: Jurisprudence and the judiciary have agreed to consider the date of issuing of the check as one of the essential data, the failure of which leads to the invalidity of the check. The importance of mentioning the date of the check is due to several considerations: the most important of which is knowing the eligibility of the drawer, because the date of issuance is the basis for assessing the extent to which the drawer enjoys eligibility or not ,this is if the date on the check is correct; knowing whether or not the elements of the crime are available, because what matters in determining whether or not the balance exists is the date of issue; knowing if the check was issued during the period of uncertainty or not in the case of bankruptcy of the drawer if he was a merchant, and that is because the trader loses eligibility to conduct legal actions, including issuing a check starting from the date of cessation of payment ${ }^{(20)}$

-The place of issuing the check: it must be mentioned in the check the place of its issuance, and it is customary that the place of the check is written next to the date of issuance of it . Mentioning the place of issuance is of great importance mainly in determining the dates for presenting the check for fulfillment, as these dates differ according to whether the check is obligatory Payment in the same place of origin, or in another place. Also, its importance appears in international checks and most of the laws conflict arising in connection with it, and for determining the applicable law : the general rule is that the form of the check is subject to the law of the country in which it was written ${ }^{(21)}$.

\section{Third: The drawee's name}

The drawee is the one who is obligated to pay the value of the check, and he is the one to whom the drawer issued the order to pay. The subject of the drawee raised a great debate at the international conference held in Geneva in 1931, and the conference was divided into three different views. The Geneva conference ended in favoring the opinion that the drawee should be a bank, and the third article stipulated: "The check is drawn on a bank that has money that the drawer can dispose of according to a check ...." . The Jordanian legislator has taken this approach by requiring that the drawee in the check be banked in accordance with the provisions of Article (230), and accordingly, the check drawn in Jordan and due to be paid in it loses its status as a check if it is drawn to a non-banker. In addition to that, he will be punished with a fine not exceeding Fifty dinars for anyone who withdraws a check on a non-bank according to Article (275/1) Jordanian Trade ${ }^{(22)}$.

Fourth: An order that is not conditional on paying a certain amount of money

The place of the check must be an amount of cash that is specified in the exact amount. It is not permissible for the check's amount to be unlimited with a rudder, such as "Pay the debt that you owe" or "Pay the agreed amount." It is also permissible to write the amount specified in the check in letters or numbers or with them together .It is customary to write the amount in letters and numbers together, and if there is a difference between them, the point is in the letters. And if the check is drawn up with one of them, the point is when the difference is the lowest amount .The check must include an order from the drawer to the drawee to pay a certain amount of cash, and any phrase may be used that states this meaning (23)

\section{Fifth: the place of fulfillment}

The place of issuance must be mentioned in the check, and this is confirmed by Article (222 / A, 
B) of the Jordanian Trade Law. It is customary that the place of the check is written next to the date of issuance of the check. Writing the place of origin is of great importance mainly in determining the dates for presenting the check for payment, as these dates differ according to whether the check is payable in the same place of origin, or in another place. Its importance also appears in international checks and the bulk of conflict of laws arising in connection with it, and for determining the applicable law. The general rule is that the form of the check is subject to the law of the country in which it was written ${ }^{(24)}$.

\section{Sixth: The signature of the drawer.}

The signature is considered a manifestation of the will, and accordingly, the signature expresses the drawer's satisfaction of the commitment fixed in the check. And in this respect, it is considered an objective condition, in addition to being one of the basic and essential data without which the check becomes devoid of all legal value, except as a principle evidenced by writing of the commitment of the drawer before the beneficiary, and accordingly, the criminal protection established for the check shall cease in case the signature on the check fails. The signature is required to be in the handwriting of the drawer or in any language, even if that contradicts the language in which the check was written, and therefore it is not permissible to use the machine for signing, as well as seals due to the ease of forgery and lack of evidence indicating the issuance of the check by the drawer when the dispute occurs. The signature must be clear and sufficient to indicate the person of the drawer, and it is usually handwritten, so if the drawer is illiterate, he may sign with the stamp or fingerprint provided that the name is mentioned.

\section{Seventh: the name of the beneficiary}

$\mathrm{He}$ is the person who writes the check in his favor, and the first creditor of the right established in it. The Jordanian legislator has permitted several methods, through what is stated in Article 233 of the Trade Law, to designate the beneficiary in the check in several ways.

\section{Eighth: The copy number when multiple copies}

The basic principle is for the check to be issued in one copy as a payment instrument. Nevertheless, the Jordanian legislator, in Article (267) of the Trade Law, authorized the issuance of the check from multiple copies in some cases, but if it was issued in several copies, these copies must be numbered, as each number is counted for each copy of mandatory data; otherwise, each copy is considered a separate form ${ }^{(25)}$.

\section{The Second Requirement}

\section{Penalty For Breaching Formal Requirements}

From the foregoing, it becomes clear to us that the check is a legal and formal act, meaning that the legislator has required that the check be written in a document and include certain data. If a check is not written in a document that is signed, it is considered void, then there is no legally valid check unless it was issued in a document, so writing is necessary in order for the check to be valid and proven. Accordingly, it is not permissible to establish evidence for the issuance of the check with proofs and clues, but if the check came free of some of the mandatory data, then the check is defective in terms of form and the effect of this defect varies according to the nature and importance of the left statement ${ }^{(26)}$.

If the dropped statement is the signature of the drawer or the amount of the check, then the check is invalid and does not have any legal effect, because these data are among the conditions necessary for the validity of the firm commitment in the check. Thus, the drawer's signature is an expression of his will in which satisfaction is provided, and the amount of the check is evidence of the obligation of the drawer ${ }^{(27) .}$

But if the abandoned statement is other than the signature of the drawer and the amount, then its abandonment will only result in the invalidation of the check as a commercial paper, and this is what Article (229/1) of the Jordanian Trade Law states: "“"A bond devoid of one of the aforementioned data is not considered a check." The check in this case is not devoid of all legal effect. Rather, it may turn into another legal action once its conditions are completed in implementation of the 
rules for the transformation of the invalid legal disposition stipulated in Article (169) of the Civil Code, and the legal disposition into which the check is converted may be another commercial paper, or it may be a normal bond ${ }^{(28)}$.

If the check does not mention the name of the drawee, it is considered a bond for an order if it was issued to the beneficiary's order because it includes the drawer's pledge to the beneficiary, and the bond is for an order that includes only two people, one of whom is a creditor and the other is a debtor. The check is also considered a regular bond if it is drawn to a non-bank, or if the order directed to the drawee is pending on a suspended or nullified condition or it refers to facts outside of the bond's data so that the check loses its selfguarantee ${ }^{(29)}$.

However, the Jordanian legislator mentioned an exception to the provision of the first paragraph of Article (229) stipulated in paragraphs (a, b, c, and d) of the same article, according to which the check was considered valid despite the absence of some mandatory data, as the data can be replaced by other data left behind in the instrument.

It is worth noting that the Jordanian legislator stipulates that the data that he stipulated in the check are all mandatory data that must be available and he arranged a legal part for violating them and leaving them, which is mentioned in Article (228) of the Jordanian Trade Law. As for the optional data, he left it to the people of the check to add what they see appropriate in terms of interest for them, provided that it does not conflict with the nature of the check or the principle of self-guarantee that governs commercial papers, such as the condition of payment in a chosen location, the condition of non-endorsement, the condition of non-guarantee, and the condition of non-return without Expenses, and the condition of paying in a foreign currency ${ }^{(30)}$.

\section{Conclusion, Findings And Recommendations}

In conclusion, this research dealt with one of the most important practical legal topics that raise many legal problems which is the formalism in commercial papers: the formalism in the check as a model, and the consequent importance and legal consequences of this formality. Accordingly, the researcher reached a set of results and recommendations, which can be summarized as follows:

\section{First: The Results}

1- It was found out that the Jordanian legislator and the Iraqi legislator referred to the mandatory data in the check as an exhaustive and not an example, by stipulating them in Article (137) of the Iraqi Trade Law, and Article (228) of the Jordanian Trade Law.

2- Formalism is of great importance in general in commercial papers and in the check in particular . The legislator has set the invalidity of the check that is empty from the date of its issuance . However, the check may include optional information that does not conflict with its nature and does not contradict any of the peremptory rules or public order and morals.

3 - If the check does not mention the name of the drawee, it is considered a bond for an order if it was issued to the beneficiary's order because it includes the drawer's pledge to the beneficiary, and the bond is for an order that includes only two people, one of whom is a creditor and the other is a debtor. The check is also considered a regular bond if it is drawn to a non-bank, or if the order directed to the drawee is pending on a suspended or nullified condition or it refers to facts outside of the bond's data so that the check loses its selfguarantee

\section{Second: Recommendations}

1- the researcher recommend the necessity to organize optional statements and indicate their importance, which do not conflict with the nature of the check, as in the case with mandatory data, and not content with referring to the provisions of other articles.

2- The researcher proposes to hold training courses for judges to introduce commercial papers and the provisions related to formalities therein, especially check, as it is one of the commercial papers affected by formalism. 


\section{References}

\section{First: Books}

[1] Al-Khalidi, Enas, A Brief in Commercial Papers according to the Saudi Commercial Paper System, House of Culture for Distribution and Publishing, Amman, 2016.

[2] Al-Sharqawi, Mahmoud Samir, Commercial Papers, Arab Renaissance House, Cairo, 1993.

[3] Al-Otair, Abdel-Qader, Mediator in Commercial Law, Commercial Papers, House of Culture for Distribution and Publishing, 1998

[4] Al-Uqaili, Aziz, Explanation of the Commercial Law: Part Two, Commercial Papers and Banking Operations, House of Culture for Distribution and Publishing, Amman, 2005.

[5] Karim, Zuhair Abbas, The Legal System of the Check, House of Culture for Distribution and Publishing, Amman, 1997.

[6] Mahmoud, Essam Hanafi, Commercial Papers: Bill, Bond, Check, Arab Renaissance House, Cairo, 2010.

[7] Yunus, Ali Hassan, Commercial Papers, The Legal Library, Beirut, 2005.

\section{University Theses:}

[1] Sultan, Ola Marwan, Legal Guarantees Supporting the Use of Check in Transactions as an Alternative to Cash, Master Thesis, Middle East University, Amman, 2010

[2] Al-Issawi, Muhammad AbdulRazzaq, Shortage of Check Data: A Comparative Study, Master Thesis, Middle East University, Amman, Jordan, 2017.

[3] Qarareih , Qusay Jihad Muhammad, The Legislative and Practical Reality of the Check: A Comparative Study, Master Thesis,
An-Najah National University, Nablus, Palestine, 2015.

\section{Third: Journals, Research And Periodicals}

[1] Issa, Noha Khaled, The Concept Of Law For The Electronic Instrument, a research published in the Al-Mohaqiq Al-Hili Journal of Legal and Political Sciences, University of Babylon, Iraq, Volume 7, Issue 3, 2015.

[2] Najm, Omar Ali, The Formal Conditions For The Instrument, published research, Tikrit University Journal of Law, Year 3, Volume 3, Issue 2, Part One, 2019.

\section{Notes}

[8] Al-Otair, Abdel-Qader, Mediator in Commercial Law, Commercial Papers, House of Culture for Distribution and Publishing, 1998 .page 114

[9] Al-Khalidi, Enas, Brief in Commercial Papers according to the Saudi Commercial Paper System, Culture House for Distribution and Publishing, Amman, 2016, p. 97.

[10] Mahmoud, Essam Hanafi, Commercial Papers: Bill, Bond, Check, Arab Renaissance House, Cairo, p. 11.

[11] Ibid . Al-Otair, Abdel-Qader, , p. 158.

[12] Ibid . Al-Khalidi, Enas, , p. 99.

[13] Ibid. Mahmoud, Essam Hanafi, , pg. 15.)

[14] Al-Sharqawi, Mahmoud Samir, Commercial Papers, Arab Renaissance House, Cairo, 1993, p. 190

[15] Yunus, Ali Hassan, Commercial Papers, The Legal Library, Beirut, 2005, p. 44.

[16] Ibid . Al-Sharqawi, Mahmoud Samir, , p. 25.

[17] Ibid .Mahmoud, Essam Hanafi, , p.20.

[18] Ibid .Yunus, Ali Hassan, , pg. 58.

[19] Ibid .Mahmoud, Essam Hanafi, , p. 21

[20] Ibid .Yunus, Ali Hassan, , p. 86.

[21] Sultan, Ola Marwan, Legal Guarantees Supporting the Use of Check in Dealings as a Substitute for Cash, Master Thesis, 
Middle East University, Amman, 2010, p.

44.

[22] Qarareih , Qusay Jihad Muhammad, The Legislative and Practical Reality of the Check: A Comparative Study, Master Thesis, An-Najah National University, Nablus, Palestine, 2015 p.88.

[23] Ibid .Yunus, Ali Hassan, , p. 58.

[24] Al-Oqili, Aziz, Explanation of the Commercial Law: Part Two, Commercial Papers and Banking Operations, House of Culture for Distribution and Publishing, Amman, 2005, p.208.

[25] Ibid. Al-Oqili, Aziz, p. 220.

[26] Ibid .Qarareih, Qusay Jihad Muhammad, , p. 44.

[27] ) Karim, Zuhair Abbas, The Legal System for Checks, The Culture House for Distribution and Publishing, Amman, 1997, p. 112.

[28] Issa, Noha Khaled, The Legal Concept of the Electronic Instrument, a research published in Al-Mohaqiq Al-Hilli Journal of Legal and Political Sciences, University of Babylon, Iraq, Volume 7, Issue 3, 2015, p.78.

[29] Al-Issawi, Muhammad Abdul-Razzaq, Shortage of Check Data: A Comparative Study, Master Thesis, Middle East University, Amman, Jordan, 2017, p.88.

[30] Ibid . Al- Oqili Aziz, , p. 216.

[31] Ibid. Al-Issawi, Muhammad AbdulRazzaq, , P.89.

[32] Ibid . Al- Oqili, Aziz, , p. 221.

[33] Najm, Omar Ali, Formality Conditions of the Instrument, Published Research, Tikrit University Journal of Law, Year 3, Volume 3, Issue 2, Part One, 2019, p. 165.

[34] Ibid. Al-Issawi, Muhammad AbdulRazzaq, , p. 90.

[35] Ibid . Al- Oqili Aziz, p. 222.

[36] This is what was decided by the Jordanian Court of Cassation in its decision No. 1298/89, issued on 28/8/1990, Adalah Center Publications.

[37] Ibid . Al- Oqili Aziz, p.227 